Research Article

\title{
Microscopic Mechanism Affecting Shear Strength in Lignin-Treated Loess Samples
}

\author{
Wei Liu $\left(\mathbb{D},{ }^{1}\right.$ Juan Wang $\left(\mathbb{D},{ }^{1}\right.$ Gaochao Lin, ${ }^{2}$ Li Wen, ${ }^{3}$ and Qian Wang $\mathbb{D}^{4}$ \\ ${ }^{1}$ Key Laboratory of Mechanics on Disaster and Environment in Western China, School of Civil Engineering and Mechanics, \\ Lanzhou University, Tianshui South Road, 222, Lanzhou 730000, Gansu Province, China \\ ${ }^{2}$ School of Civil and Environmental Engineering, University of New South Wales, Sydney, Australia \\ ${ }^{3}$ School of Information Science and Technology, Lanzhou University, Lanzhou 730000, China \\ ${ }^{4}$ Key Laboratory of Loess Earthquake Engineering, China Earthquake Administration in Gansu Province, Donggang West Road, \\ 450, Lanzhou 730000, Gansu Province, China
}

Correspondence should be addressed to Qian Wang; wangq0930@126.com

Received 18 December 2018; Accepted 20 March 2019; Published 16 May 2019

Academic Editor: Dimitrios E. Manolakos

Copyright (C) 2019 Wei Liu et al. This is an open access article distributed under the Creative Commons Attribution License, which permits unrestricted use, distribution, and reproduction in any medium, provided the original work is properly cited.

In China, engineers have worked to create additional usable land for building construction by flattening the ridges of hills and filling in the adjacent valleys. China's Loess Plateau comprises a type of soil (loess) with a large pore structure that can collapse and become unstable when exposed to groundwater. Conventional valley fill materials include remolded loess or remolded loess treated with cement, lime, gypsum, or other stabilizing additives. These stabilizers are often detrimental to the surrounding environment. Moreover, loess treated with conventional stabilizers exhibits excessive brittleness, which is not suitable for building foundations. Adequate stability of the building foundations in the filled valleys is required to ensure public safety. In this study, we tested 50 remolded loess samples treated with a lignin polymer compound to determine its potential as a valley fill material. Triaxial tests, scanning electron microscopy (SEM), and X-ray diffraction (XRD) were used to study the mechanical characteristics of each sample, determine the effects of the lignin treatment on the loess, and identify the microscopic mechanism affecting shear stress in the lignin-treated loess. The corresponding development of excess pore pressure and volumetric responses under monotonic triaxial testing were also considered. Based on this study's results, the optimum lignin content in the treated loess samples was $4 \%$; lignin contents exceeding $4 \%$ decreased axial stress and increased dilation after saturation. The shear strength and strain-hardening phenomenon of the lignin-treated loess samples increased as the lignin content increased, while the excess pore water pressure decreased. Microscopically, the addition of lignin increased cohesion in the loess samples, while slightly contributing to the internal friction angle. The use of lignin as a stabilizing additive for valley fill material shows potential for controlling building foundation deformation by increasing soil strength and minimizing environmental impacts by maintaining the soil $\mathrm{pH}$ and limiting pollutant production.

\section{Introduction}

Loess - a type of soil with a large pore structure-is found all over the world including in Asia, Europe, and North and South America $[1,2]$. In China, loess is primarily concentrated in the north and northwest areas of the country. The mechanical properties of loess are affected by water content [3], strain rate [4], and degree of saturation [5]. Most importantly, loess can collapse and become unstable when exposed to groundwater. Figure 1 depicts how the ground surface can be eroded by water.

In China, engineers have worked to create additional usable land for building construction by flattening the ridges of hills and filling in the adjacent valleys. They are now applying these same land creation processes in the north and northwest areas of the country where loess concentrations are high. These areas are near the cities of Lanzhou and Yan'an in the Gansu and Shanxi Provinces, respectively. 


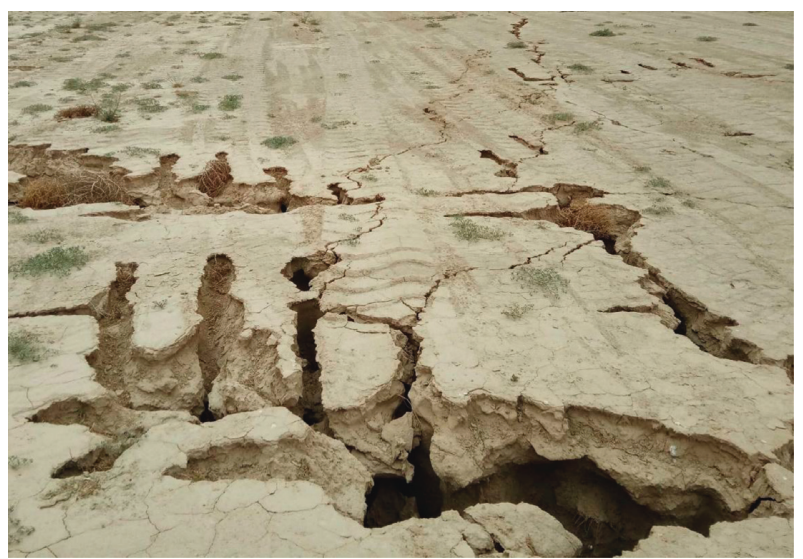

Figure 1: Loess is eroded by water.

Figure 2 depicts the Gansu Province, which was considered in this study.

Conventional valley fill materials include remolded loess or remolded loess treated with cement, lime, gypsum, or other stabilizing additives. These stabilizers are often detrimental to the surrounding environment [6]. Moreover, loess treated with conventional stabilizers exhibits excessive brittleness, which is not suitable for building foundations. In fact, Lim et al. [7] purported that loess could be used as a modifier in the treatment of sludge because of its engineering properties. Adequate stability of the building foundations in the filled valleys is required to ensure public safety. To minimize building foundation deformation and environmental impacts, various scholars have investigated the effects of these stabilizing additives on loess used as a valley fill material.

Cuisinier et al. [8] found that the addition of lime decreased the maximum dry density of the loess and concurrently affected the hydraulic conductivity of the treated soil. Similarly, Gao et al. [9] found that the addition of lime changed the structure of the loess, affecting its mechanical and hydraulic properties and its associated bearing capacity and water flow. The addition of both lime and fly ash has been found to increase the shear strength and compressibility of loess. Zhang et al. [10] conducted a series of tests to determine the effects of admixture materials and concentrations on the shear strength of loess over an extended period. The strength gain and stability over time in the loess samples treated with lime or lime-fly ash combinations were attributable to the working time of the additives. The hydration reaction rate was an important factor affecting the performance of the loess samples treated with lime. Zhang et al. [11] conducted a similar study that considered cement as the additive. The addition of cement increased the shear strength of the loess; the compressibility strength of the loess was dependent upon the cement content. These same researchers noted that cohesion was more sensitive to structure than friction angle in cement-treated loess samples. Most recently, Zhang et al. [12] used acid solutions to improve the pore structure and associated mechanical properties of loess. Soluble salt crystals found in the cement additive $\left(\mathrm{CaCO}_{3}\right)$ and in the loess were dissolved using acid

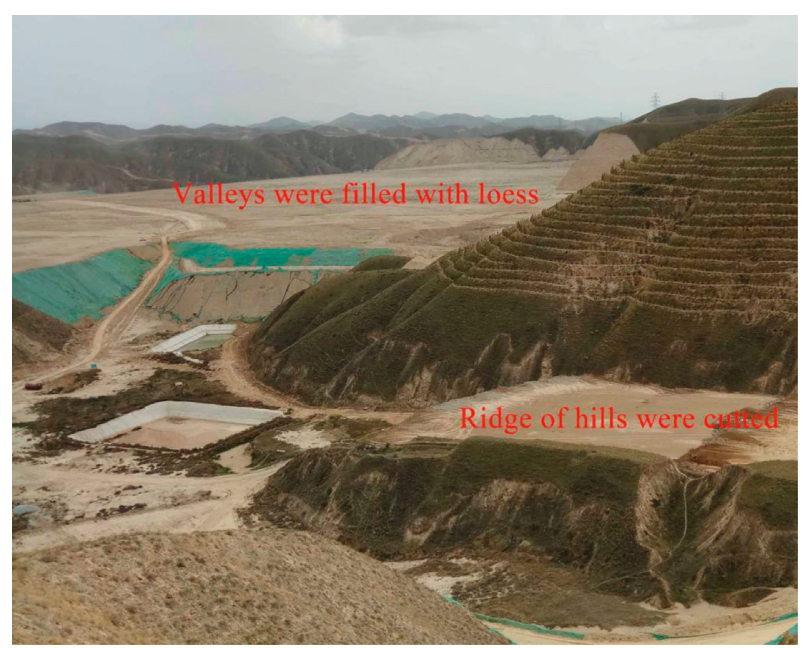

Figure 2: Land creation engineering.

solutions to produce a new and stable cement-treated loess structure.

Results from these previous studies have demonstrated that the use of conventional stabilizing additives (cement, lime, and fly ash) is effective in improving the shear strength and compressibility of loess and has subsequently encouraged the widespread use of loess as a fill material in geotechnical engineering applications. However, the use of these conventional stabilizers has been found to have a detrimental effect on the environment although this topic has received much less scholarly focus. Rollings et al. [13] found that chemical admixtures intended to stabilize a soil changed the $\mathrm{pH}$ level of the soil, limited the scope of vegetation, and affected the quality of the groundwater. Kitchen et al. [14] found that these chemical admixtures decreased the waterretaining and nutrient-carrying capacities of a soil. As a result, soil fertility is generally weakened by these chemical admixtures; grass and trees exposed to the chemical admixtures will gradually die. Nalbantoglu and Tuncer [15] found that the excessive use of chemical admixtures to stabilize soil affects the yielding capacity of certain soils, which may in turn result in a brittle and unstable soil.

An environmentally friendly alternative to the conventional stabilizing additives of cement, lime, and fly ash used to improve the strength and durability of loess is required. Lignin-a polymer compound produced in the paper industry-has shown some potential for stabilizing unstable soil [16-18]. Zhang et al. [19-22] conducted series of laboratory tests to evaluate the effects of the lignin concentration and curing time on soil properties. Researchers considered each sample's Atterberg limits, $\mathrm{pH}$, unconfined compressive strength, stress-strain characteristics, and thermal and mechanical properties. Scanning electron microscopy (SEM), X-ray diffraction (XRD), and ercury intrusion porosimetry (MIP) were used to understand the microstructural characteristics and stabilization mechanism of the stabilized silt. Results from this study indicated that lignin generally improved the basic engineering properties and microstructural characteristics of silt but was dependent upon both the lignin concentration and curing time. 
Canakci et al. [23] conducted a more limited series of tests comparing the performance of lignin, rice husk powder, and rice husk ash as stabilizing additives. Both the additive material and curing time affected each soil sample's unconfined compressive strength. As the additive content increased, the soil's liquid limit decreased while its plastic limit increased.

Lignin offers several advantages over the conventional stabilizing additives of cement, lime, and fly ash. Lignin is less costly, more environmentally friendly, and readily available. Over 50 million tons of industrial lignin is produced worldwide annually [24]. Previous studies have primarily focused on the unconfined compression strength of various soil types following lignin treatment. None of the previous studies has considered the performance of lignintreated loess, particularly under saturation conditions. The valley fill material becomes easily saturated when rainfall and irrigation runoff infiltrate the valleys.

In this study, we tested 50 remolded loess samples treated with lignin to determine its potential as a valley fill material. Triaxial tests, including unconfined compression (UC), isotropically consolidated undrained compression (ICUC), and consolidated drained compression (CDC) shearing tests, were used to study the mechanical characteristics of each sample and determine the effects of the lignin treatment on the loess. In addition, SEM and XRD were used to identify the microscopic mechanism affecting shear stress in the lignin-treated loess. The corresponding development of excess pore pressure and volumetric responses under monotonic triaxial testing were also considered.

\section{Materials and Methods}

2.1. Materials. To support testing in this study, loess was acquired in northwestern China near the city of Lanzhou in the Gansu Province at a depth of $10.5-12.5 \mathrm{~m}$. Figure 3 shows the general location of this material source. The loess comprised $75.25 \%$ silt, $16.45 \%$ clay, and $8.30 \%$ sand that collectively offered a high porosity and volume of voids. Figure 4 shows the particle size distribution curve for this material. Minimal roots or other organic matter were found in the loess; organic matter often has a profound effect on the particle size distribution of the sediment samples [25]. The specific mineral composition of the loess included hornblende, gypsum, quartz, feldspar, calcite, pyroxene, and kaolin. The water content and density of the loess were $4.25-5.04 \%$ and $1.41 \mathrm{~g} / \mathrm{cm}^{3}$ (American Society for Testing and Materials [26]), respectively. The optimum water content and maximum dry density of the loess were $14.72 \%$ and $1.71 \mathrm{~g} / \mathrm{cm}^{3}$, respectively, according to the standard Proctor compaction test. The liquid and plastic limits of the loess were $29.30 \%$ and $19.40 \%$, respectively [27].

The lignin used in this study was in the form of a nontoxic white powder that was soluble in water. Lignin, a polymer compound produced in the papermaking industry, contains hydrophilic groups including sulfonate, phenylic hydroxyl, and alcoholic hydroxyl and hydrophobic groups including the carbon chain [28].
2.2. Soil Sample Preparation. In the laboratory, the loess was initially dried for 7-10 days to ensure a stable water content. A mortar was then used to crush the dry loess. The loess was subsequently sieved in preparation for testing.

Prepared samples included both treated and untreated loess. Treated loess samples were prepared using five lignin concentrations $(0,1,2,3$, and $4 \%)$ based on the dry loess weight. Samples initially prepared with lignin concentrations higher than $4 \%$ became seriously dilated when saturated using the vacuum saturation method. Thus, the results for samples with $5 \%$ lignin were consistent with the results for samples with $4 \%$ lignin, eliminating the need to prepare and consider samples with lignin concentrations higher than $4 \%$. The required amount of lignin was first mixed with the loess. Water was then added until the optimum water content was reached.

Specimens were prepared using static compaction with controlled static stress and axial displacement. After pouring the required amount of loess into the stainless steel barrel, the stainless steel head was lowered onto one side of the sample with a load, producing a half axial displacement. Figure 5 depicts this process. Next, the stainless steel head was lowered onto the other side of the sample with a load, producing the full axial displacement. The samples were removed from the stainless steel barrel and compacted into uniform specimens using static compaction methods via a ack system. The final samples measured $50 \mathrm{~mm}$ in diameter and $100 \mathrm{~mm}$ in height, with $10 \%$ water content and 0.96 degree of compaction. The compacted samples were then sealed in plastic wrap and stored in a temperaturecontrolled environment with a constant temperature of $25 \pm 2^{\circ} \mathrm{C}$ to cure for up to 36 days.

2.3. Test Methods. To investigate the shear strength of lignintreated loess, UC, ICUC, and CDC tests were conducted on samples that were cured for 28 days. Preliminary UC test results for samples cured for $0,4,8,12,16,20,24,28,32$, and 36 days revealed that the shear strength of the loess increased only marginally for cure times in excess of 28 days. Table 1 details the testing scheme followed in this study.

To best reflect the field conditions near the cities of Lanzhou and Yan'an in the Gansu and Shanxi Provinces, respectively, all triaxial tests were performed on saturated specimens. In the newly created land areas in Lanzhou and Yan'an, many of the filled valleys remain low-lying, with the groundwater level very close to the new ground surface. In these areas, full saturation is common. Rainfall and irrigation runoff will further infiltrate the filled valleys; the fill material encourages the horizontal movement of water throughout its mass, ensuring full saturation in low-lying areas.

Prior to ICUC and CDC testing, vacuum saturation methods were used to saturate the specimens for more than $24 \mathrm{hr}$. Next, back pressure saturation methods were used until each sample's $B$ value was greater than 0.98 . Finally, each sample was isotropically consolidated under a given effective confining pressure. A backpressure approaching $350 \mathrm{kPa}$ was required to reach a high degree of saturation. 


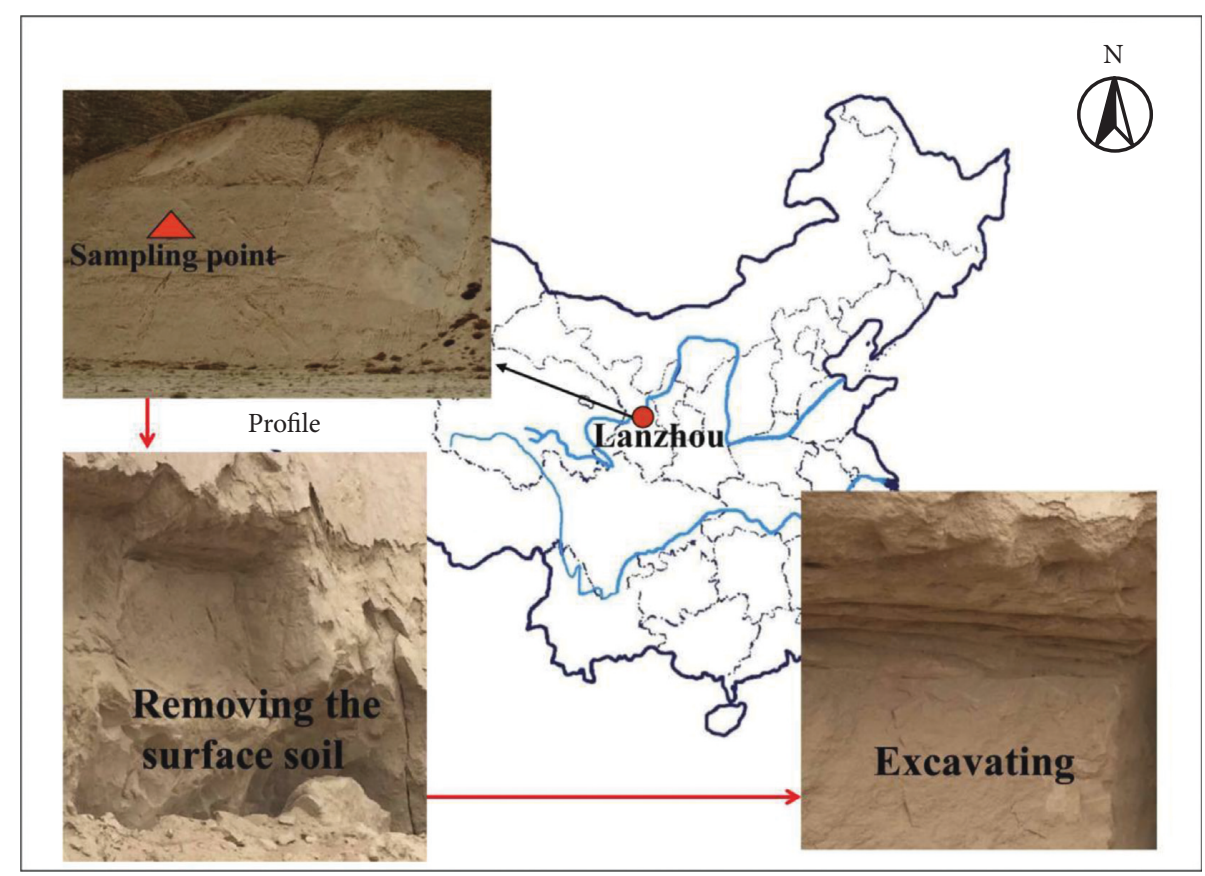

Figure 3: Location of the research area and the sampling points.

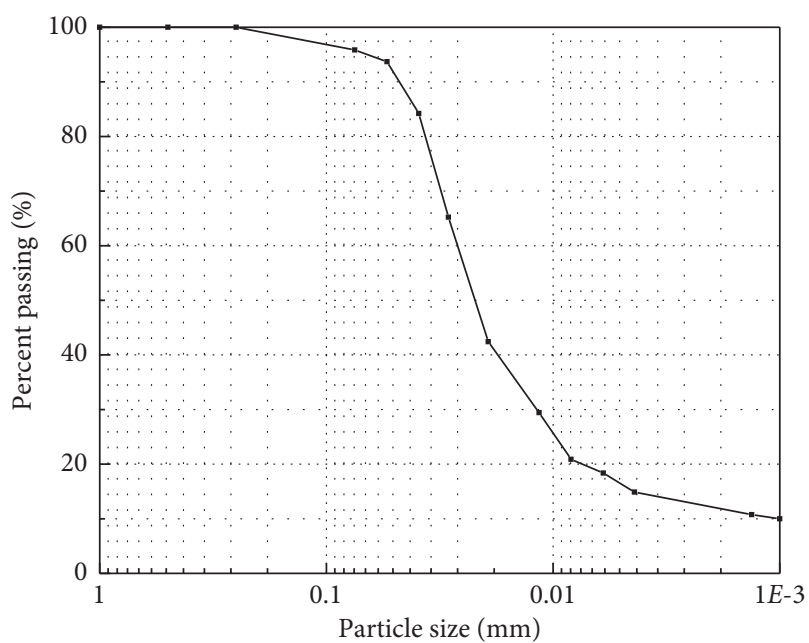

Figure 4: Particle size distribution curve of loess soil.

The cell pressure and back pressure were applied incrementally and allowed to stabilize for $60 \mathrm{~min}$ after reaching their target value [5].

To additionally reflect the field conditions near Lanzhou and Yan'an, effective confining pressures used in the triaxial tests were determined based on the in situ conditions of these areas. The valley depths near Lanzhou and Yan'an range from 6.0 to $36.0 \mathrm{~m}$. Based on these depths, effective confining pressures were calculated as a function of the soil density and the coefficient of arth pressure at rest $\left(K_{0}\right)$ [29]. Thus, effective confining pressures of 80,140,200, and $300 \mathrm{kPa}$ were applied to the loess samples during ICUC and $\mathrm{CDC}$ testing to represent in situ conditions. The shearing rates in the ICUC and CDC tests were 0.05 and $0.005 \mathrm{~mm} /$ min, respectively. Results from each of the triaxial tests were

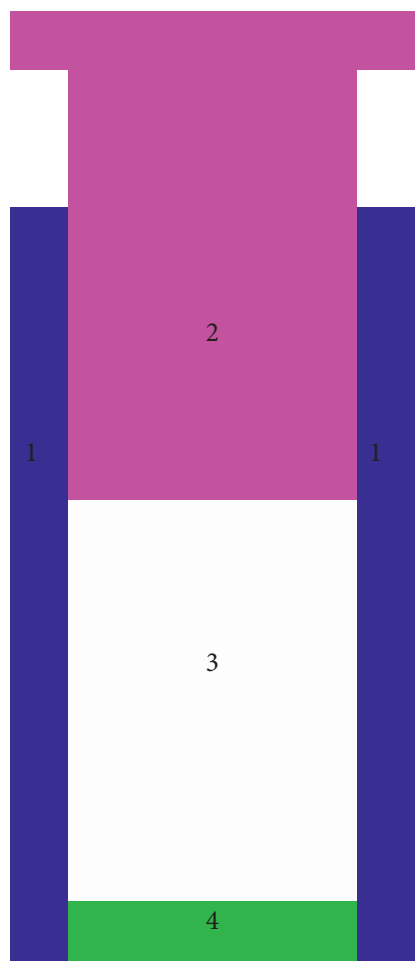

FIGURE 5: Mould of compacting samples. (1) Stainless steel barrel. (2) Stainless steel head. (3) Soil. (4) Heel block.

reported for axial strains up to $20 \%$, which was the limit of the load actuator. The total volume change for each of the samples in the CDC tests was measured using a volume change sensor [5].

In addition to the triaxial tests, SEM and XRD were used to identify the microscopic mechanism affecting shear 
TABLE 1: Summary of tests in the study.

\begin{tabular}{|c|c|c|c|c|c|c|c|}
\hline Samples & Moisture content (\%) & Density $\left(\mathrm{g} / \mathrm{cm}^{3}\right)$ & Plastic limit (\%) & Liquid limit (\%) & Void ratio & Specific gravity & Test type \\
\hline MZS-0 & 9.11 & 1.73 & 26.08 & 16.31 & 0.71 & 2.71 & UC \\
\hline MZS-1 & 9.63 & 1.73 & 31.25 & 19.28 & 0.71 & 2.70 & UC \\
\hline MZS-2 & 9.65 & 1.73 & 33.12 & 18.09 & 0.70 & 2.69 & UC \\
\hline MZS-3 & 9.53 & 1.72 & 37.90 & 21.69 & 0.71 & 2.68 & $\mathrm{UC}$ \\
\hline MZS-4 & 9.51 & 1.72 & 43.17 & 21.70 & 0.69 & 2.66 & UC \\
\hline MZS-0 & 9.46 & 1.73 & 26.08 & 16.31 & 0.71 & 2.71 & $\mathrm{ICUC}+80 \mathrm{kPa}$ \\
\hline MZS-1 & 9.44 & 1.73 & 31.25 & 19.28 & 0.71 & 2.70 & $\mathrm{ICUC}+80 \mathrm{kPa}$ \\
\hline MZS-2 & 9.27 & 1.73 & 33.12 & 18.09 & 0.70 & 2.69 & $\mathrm{ICUC}+80 \mathrm{kPa}$ \\
\hline MZS-3 & 9.29 & 1.73 & 37.90 & 21.69 & 0.69 & 2.68 & $\mathrm{ICUC}+80 \mathrm{kPa}$ \\
\hline MZS-4 & 9.52 & 1.73 & 43.17 & 21.70 & 0.68 & 2.66 & ICUC $+80 \mathrm{kPa}$ \\
\hline MZS-0 & 9.61 & 1.73 & 26.08 & 16.31 & 0.72 & 2.71 & $\mathrm{ICUC}+140 \mathrm{kPa}$ \\
\hline MZS-1 & 9.96 & 1.72 & 31.25 & 19.28 & 0.73 & 2.70 & $\mathrm{ICUC}+140 \mathrm{kPa}$ \\
\hline MZS-2 & 9.78 & 1.72 & 33.12 & 18.09 & 0.72 & 2.69 & $\mathrm{ICUC}+140 \mathrm{kPa}$ \\
\hline MZS-3 & 10.12 & 1.72 & 37.90 & 21.69 & 0.72 & 2.68 & $\mathrm{ICUC}+140 \mathrm{kPa}$ \\
\hline MZS-4 & 10.08 & 1.72 & 43.17 & 21.70 & 0.70 & 2.66 & $\mathrm{ICUC}+140 \mathrm{kPa}$ \\
\hline MZS-0 & 10.11 & 1.72 & 26.08 & 16.31 & 0.73 & 2.71 & $\mathrm{ICUC}+200 \mathrm{kPa}$ \\
\hline MZS-1 & 10.15 & 1.72 & 31.25 & 19.28 & 0.73 & 2.70 & $\mathrm{ICUC}+200 \mathrm{kPa}$ \\
\hline MZS-2 & 10.55 & 1.72 & 33.12 & 18.09 & 0.73 & 2.69 & $\mathrm{ICUC}+200 \mathrm{kPa}$ \\
\hline MZS-3 & 10.32 & 1.73 & 37.90 & 21.69 & 0.71 & 2.68 & $\mathrm{ICUC}+200 \mathrm{kPa}$ \\
\hline MZS-4 & 10.29 & 1.73 & 43.17 & 21.70 & 0.70 & 2.66 & $\mathrm{ICUC}+200 \mathrm{kPa}$ \\
\hline MZS-0 & 10.32 & 1.73 & 26.08 & 16.31 & 0.73 & 2.71 & $\mathrm{ICUC}+300 \mathrm{kPa}$ \\
\hline MZS-1 & 10.53 & 1.74 & 31.25 & 19.28 & 0.72 & 2.70 & $\mathrm{ICUC}+300 \mathrm{kPa}$ \\
\hline MZS-2 & 9.46 & 1.73 & 33.12 & 18.09 & 0.70 & 2.69 & $\mathrm{ICUC}+300 \mathrm{kPa}$ \\
\hline MZS-3 & 9.44 & 1.73 & 37.90 & 21.69 & 0.70 & 2.68 & $\mathrm{ICUC}+300 \mathrm{kPa}$ \\
\hline MZS-4 & 9.27 & 1.73 & 43.17 & 21.70 & 0.68 & 2.66 & $\mathrm{ICUC}+300 \mathrm{kPa}$ \\
\hline MZS-0 & 9.29 & 1.73 & 26.08 & 16.31 & 0.71 & 2.71 & $\mathrm{CDC}+80 \mathrm{kPa}$ \\
\hline MZS-1 & 9.52 & 1.72 & 31.25 & 19.28 & 0.72 & 2.70 & $\mathrm{CDC}+80 \mathrm{kPa}$ \\
\hline MZS-2 & 9.61 & 1.72 & 33.12 & 18.09 & 0.71 & 2.69 & $\mathrm{CDC}+80 \mathrm{kPa}$ \\
\hline MZS-3 & 9.96 & 1.72 & 37.90 & 21.69 & 0.71 & 2.68 & $\mathrm{CDC}+80 \mathrm{kPa}$ \\
\hline MZS-4 & 9.78 & 1.72 & 43.17 & 21.70 & 0.70 & 2.66 & $\mathrm{CDC}+80 \mathrm{kPa}$ \\
\hline MZS-0 & 10.12 & 1.72 & 26.08 & 16.31 & 0.74 & 2.71 & $\mathrm{CDC}+140 \mathrm{kPa}$ \\
\hline MZS-1 & 10.08 & 1.73 & 31.25 & 19.28 & 0.72 & 2.70 & $\mathrm{CDC}+140 \mathrm{kPa}$ \\
\hline MZS-2 & 10.11 & 1.73 & 33.12 & 18.09 & 0.71 & 2.69 & $\mathrm{CDC}+140 \mathrm{kPa}$ \\
\hline MZS-3 & 10.15 & 1.73 & 37.90 & 21.69 & 0.71 & 2.68 & $\mathrm{CDC}+140 \mathrm{kPa}$ \\
\hline MZS-4 & 10.55 & 1.74 & 43.17 & 21.70 & 0.69 & 2.66 & $\mathrm{CDC}+140 \mathrm{kPa}$ \\
\hline MZS-0 & 10.29 & 1.73 & 26.08 & 16.31 & 0.73 & 2.71 & $\mathrm{CDC}+200 \mathrm{kPa}$ \\
\hline MZS-1 & 10.32 & 1.73 & 31.25 & 19.28 & 0.72 & 2.70 & $\mathrm{CDC}+200 \mathrm{kPa}$ \\
\hline MZS-2 & 10.53 & 1.73 & 33.12 & 18.09 & 0.72 & 2.69 & $\mathrm{CDC}+200 \mathrm{kPa}$ \\
\hline MZS-3 & 9.46 & 1.73 & 37.90 & 21.69 & 0.70 & 2.68 & $\mathrm{CDC}+200 \mathrm{kPa}$ \\
\hline MZS-4 & 9.44 & 1.72 & 43.17 & 21.70 & 0.69 & 2.66 & $\mathrm{CDC}+200 \mathrm{kPa}$ \\
\hline MZS-0 & 9.27 & 1.74 & 26.08 & 16.31 & 0.70 & 2.71 & $\mathrm{CDC}+300 \mathrm{kPa}$ \\
\hline MZS-1 & 9.29 & 1.73 & 31.25 & 19.28 & 0.71 & 2.70 & $\mathrm{CDC}+300 \mathrm{kPa}$ \\
\hline MZS-2 & 9.52 & 1.73 & 33.12 & 18.09 & 0.70 & 2.69 & $\mathrm{CDC}+300 \mathrm{kPa}$ \\
\hline MZS-3 & 9.88 & 1.73 & 37.90 & 21.69 & 0.70 & 2.68 & $\mathrm{CDC}+300 \mathrm{kPa}$ \\
\hline MZS-4 & 1.02 & 1.73 & 43.17 & 21.70 & 0.55 & 2.66 & $\mathrm{CDC}+300 \mathrm{kPa}$ \\
\hline MZS-0 & 10.06 & 1.72 & 26.08 & 16.31 & 0.73 & 2.71 & $\mathrm{SEM}+\mathrm{XRD}$ \\
\hline MZS-1 & 9.97 & 1.72 & 31.25 & 19.28 & 0.73 & 2.70 & $\mathrm{SEM}+\mathrm{XRD}$ \\
\hline MZS-2 & 9.83 & 1.72 & 33.12 & 18.09 & 0.72 & 2.69 & $\mathrm{SEM}+\mathrm{XRD}$ \\
\hline MZS-3 & 9.65 & 1.72 & 37.90 & 21.69 & 0.71 & 2.68 & $\mathrm{SEM}+\mathrm{XRD}$ \\
\hline MZS-4 & 9.67 & 1.72 & 43.17 & 21.70 & 0.70 & 2.66 & $\mathrm{SEM}+\mathrm{XRD}$ \\
\hline
\end{tabular}

stress in the lignin-treated loess. Prior to SEM analysis, the loess samples were first freeze-dried and then positioned with an adhesive paste on a flat surface and sprayed with a conductive gold coating. The prepared samples were analyzed using a scanning electron microscope (KYKY2800B) with amplifications of 100, 200, 500, and 600. Similarly, the freeze-dried loess samples were positioned on a glass wafer and subsequently analyzed in the $\mathrm{X}$-ray chamber.

\section{Experimental Results and Discussion}

3.1. Unconfined Compression (UC) Test. Figure 6 shows the unconfined compression strength of the loess samples containing lignin concentrations of $0,1,2,3$, or $4 \%$. The peak axial stress was highest in the samples containing $4 \%$ lignin. The peak axial stress increased as the lignin content increased from 0 to $4 \%$ but decreased when the lignin content exceeded 4\%. Furthermore, the samples with lignin 


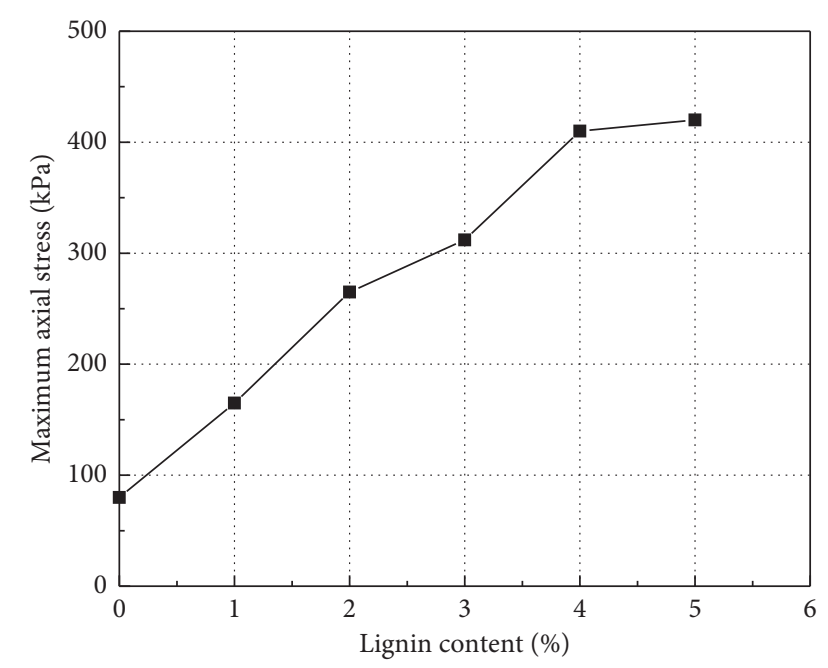

FIGURE 6: UCS results of treated loess.

concentrations exceeding $4 \%$ were easily dilated after saturation. Thus, $4 \%$ was determined to be the optimum lignin content for the treated loess to effectively control building foundation deformation.

\subsection{Isotropically Consolidated Undrained Compression} (ICUC) Test. Figure 7 shows the isotropically consolidated undrained compression strength and shear behavior of the loess samples containing lignin concentrations of $0,1,2,3$, or $4 \%$ under different effective confining pressures. The maximum deviator stress ranged from 126.59 to $518.85 \mathrm{kPa}$, and the maximum pore water pressure ranged from 31.01 to $186.30 \mathrm{kPa}$.

As shown in Figure 7 (left), the deviator stress generally increased as the lignin content increased; however, the undrained stress-strain behavior differed in the treated (1-4\% lignin) and untreated (0\% lignin) loess samples. The stress-strain relationship showed a strain-softening behavior in the untreated loess samples but a strainhardening behavior for the treated loess samples. This finding suggests that the addition of lignin could reduce the softening behavior of loess and is consistent with previously reported findings by Vinod and Indraratna [30]. However, this stress-strain relationship also suggests that the lignin-treated loess fill material used in the valleys would experience continuous deformation rather than brittle behavior. This phenomenon would affect the stability of building foundations if the fill materials became saturated by groundwater.

The peak deviator stress also rapidly increased as the effective confining pressure increased. In the untreated $(0 \%$ lignin) loess samples, the residual stress was significant following the peak deviator stress. In the treated (1-4\% lignin) loess samples, the deviator stresses increased continuously until the axial strain exceeded $15 \%$. The deviator stress amplitude also increased as the effective confining pressure increased. As shown in Figure 7 (left), the postpeak ductility of the lignin-treated loess continued to increase, contrary to the ductile-to-brittle response observed for soil treated with conventional stabilizing additives such as lime or cement [31,32].

As shown in Figure 7 (right), the relationship between excess pore water pressure and axial strain under different effective confining pressures also differed in the treated (1-4\% lignin) and untreated (0\% lignin) loess samples. The pore water pressure in each of the samples peaked with initial axial strains of $0-3 \%$. As the axial strains exceeded $3 \%$, the pore water pressure decreased in the treated samples but continued to increase slowly in the untreated samples. This finding is consistent with the previously reported stress-strain behavior in Figure 7 (left) and suggests that the increasing pore water pressure in the untreated samples could reduce the effective deviator stress in the ICUC tests. The addition of lignin in the treated samples caused the pore water pressure to decrease after reaching its peak value. This decrease in pore water pressure increased the effective deviator stress as the axial strain increased. Note that the samples with an effective confining pressure of $80 \mathrm{kPa}$ showed a peak followed by a sudden drop in pore water pressure, and negative pore water pressure or suction was produced. Comparatively, the pore water pressures remained positive for effective confining pressures of 140,200, and $300 \mathrm{kPa}$. The occurrence of negative pore water pressure was a function of the dilatancy of the samples and the effective confining pressures in the tests. As the lignin content increased, the pore water pressure decreased but the deviator stress increased under consistent confining pressures.

3.3. Consolidated Drained Compression (CDC) Test. Figure 8 shows the consolidated drained compression strength and shear behavior of the loess samples containing lignin concentrations of $0,1,2,3$, or $4 \%$ under different effective confining pressures.

As shown in Figure 8 (left), the deviator stress generally increased as the effective confining pressure and axial strain increased; however, the undrained stress-strain behavior again differed in the treated (1-4\% lignin) and untreated ( $0 \%$ lignin) loess samples. In the treated samples, the addition of lignin significantly increased the peak deviator stress, particularly at the $80 \mathrm{kPa}$ effective confining pressure. As the lignin content increased, the shear strength increased across all samples. In the treated (1-4\% lignin) loess samples, the shear strength remained stable until the peak stress was reached. The peak shear strength in the samples ranged from 202.82 to $822.02 \mathrm{kPa}$.

As shown in Figure 8 (right), the volumetric response and axial strain in the treated (1-4\% lignin) and untreated ( $0 \%$ lignin) loess samples differed under different effective confining pressures. Across all samples, a dilative response was observed for samples tested at low confining pressures (80 and $140 \mathrm{kPa}$ ), while a contractive response was observed for samples subjected to higher confining pressures (200 and $300 \mathrm{kPa}$ ). The volumetric strain changed from dilation to compression as the effective confining pressure increased 

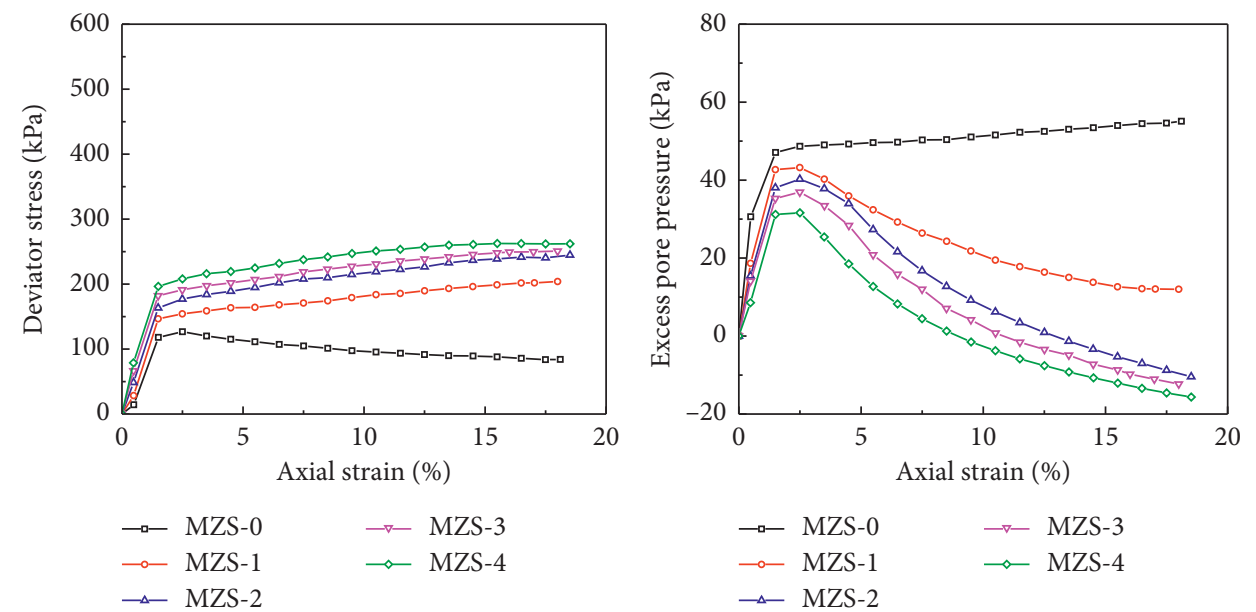

(a)
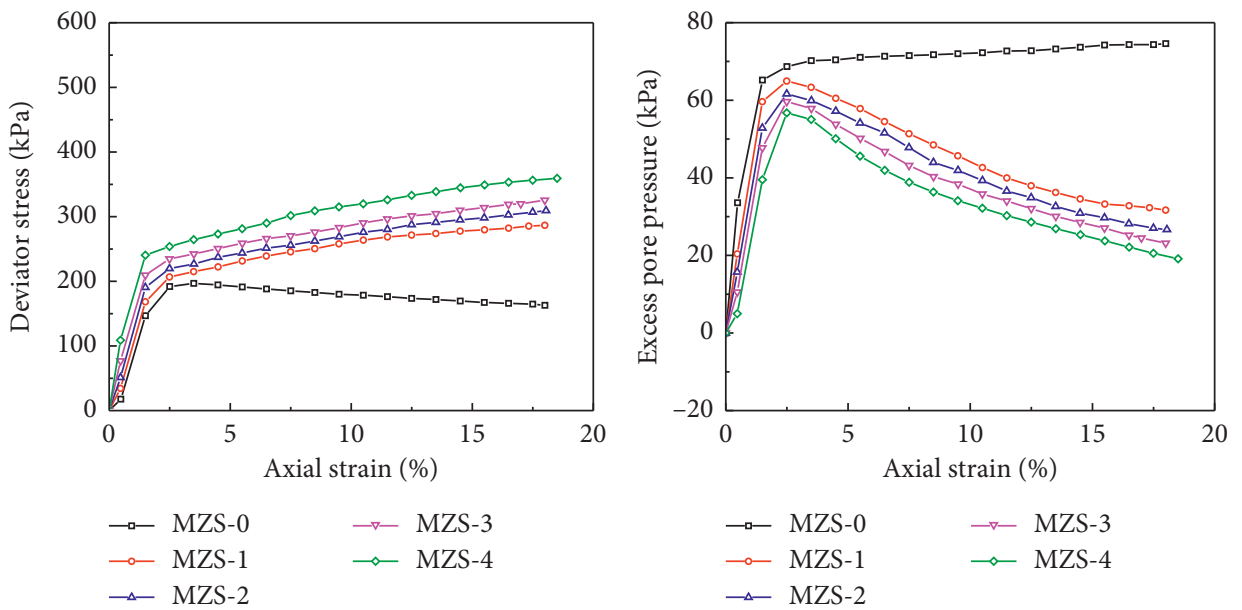

(b)
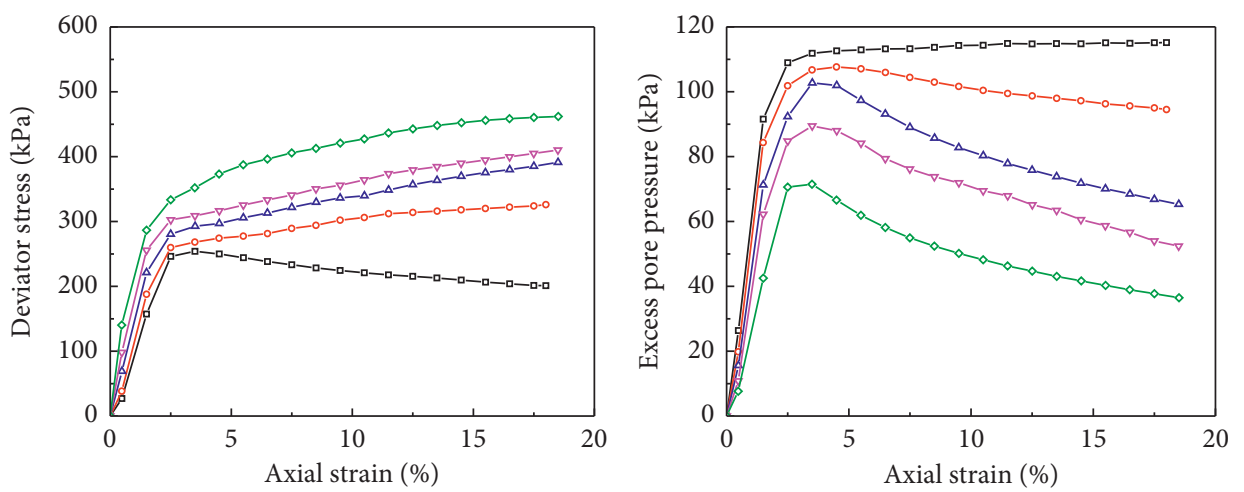
$\rightarrow-$ MZS-0
$\rightarrow-$ MZS-3
$\begin{array}{lll}\multimap \text { MZS-0 } & \rightarrow-\text { MZS-3 } \\ \multimap \text { MZS-1 } & \rightarrow \text { MZS-4 }\end{array}$
$\triangle$ MZS-2
$\rightarrow$ MZS-2

(c)

FIgURE 7: Continued. 

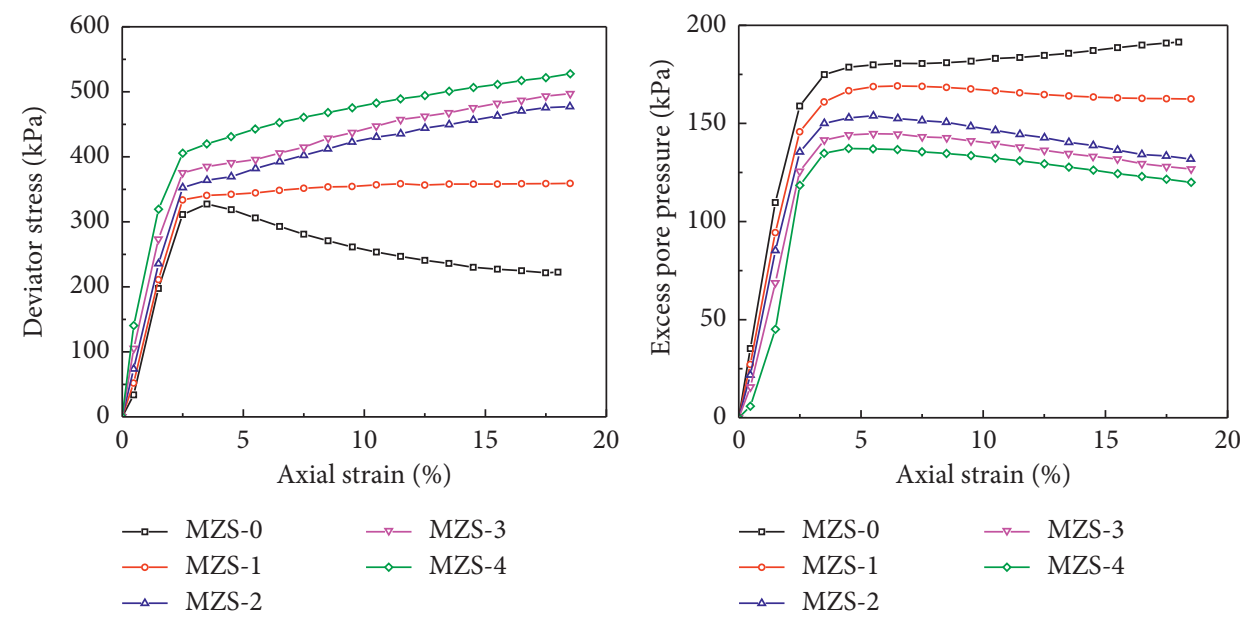

(d)

FIGURE 7: Undrained shear (ICUC) behavior of treated loess with different contents of lignin at different effective confining pressures. (a) $80 \mathrm{kPa}$. (b) $140 \mathrm{kPa}$. (c) $200 \mathrm{kPa}$. (d) $300 \mathrm{kPa}$.
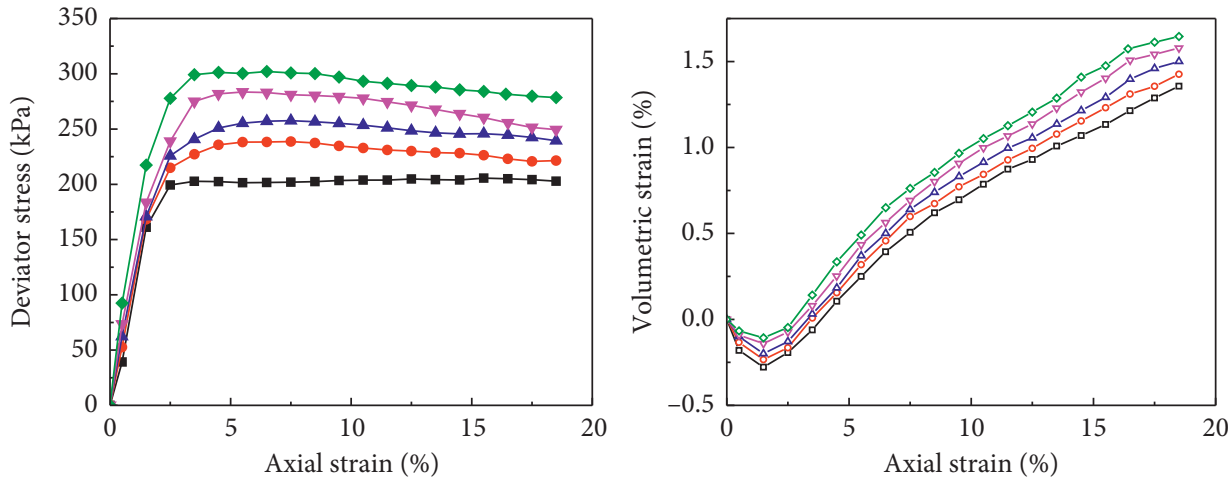

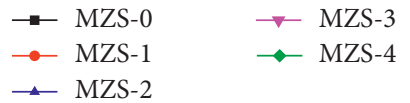

(a)

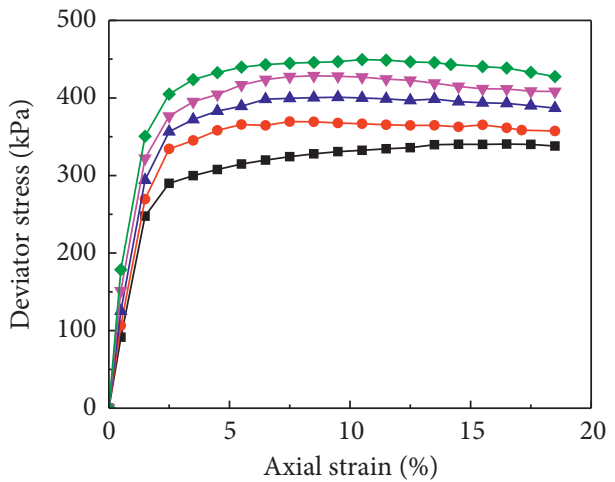

$\rightarrow-M Z S-0$

$\multimap$ MZS-1

$\triangle \mathrm{MZS}-2$

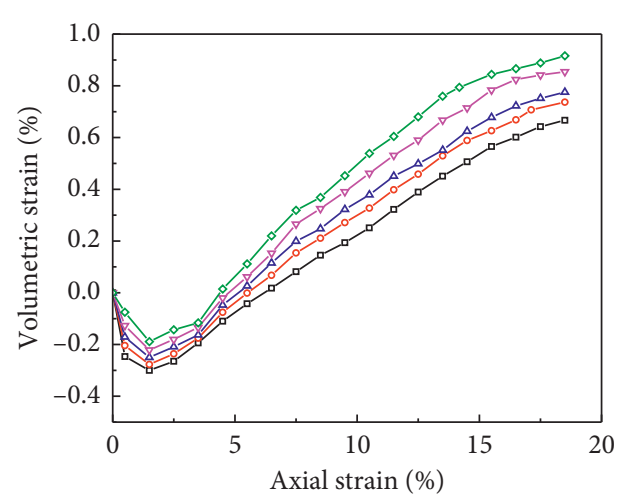

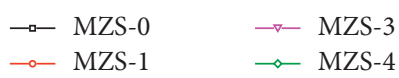

$\rightarrow \mathrm{MZS}-2$

$\rightarrow$ MZS-3

)

FIgURE 8: Continued. 

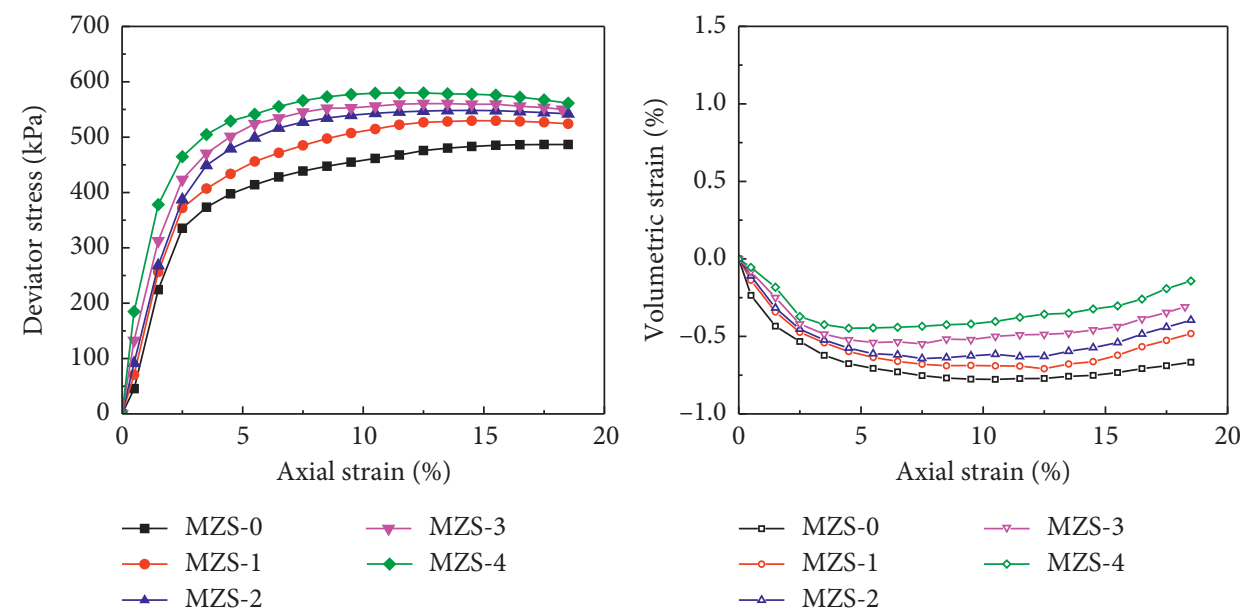

(c)
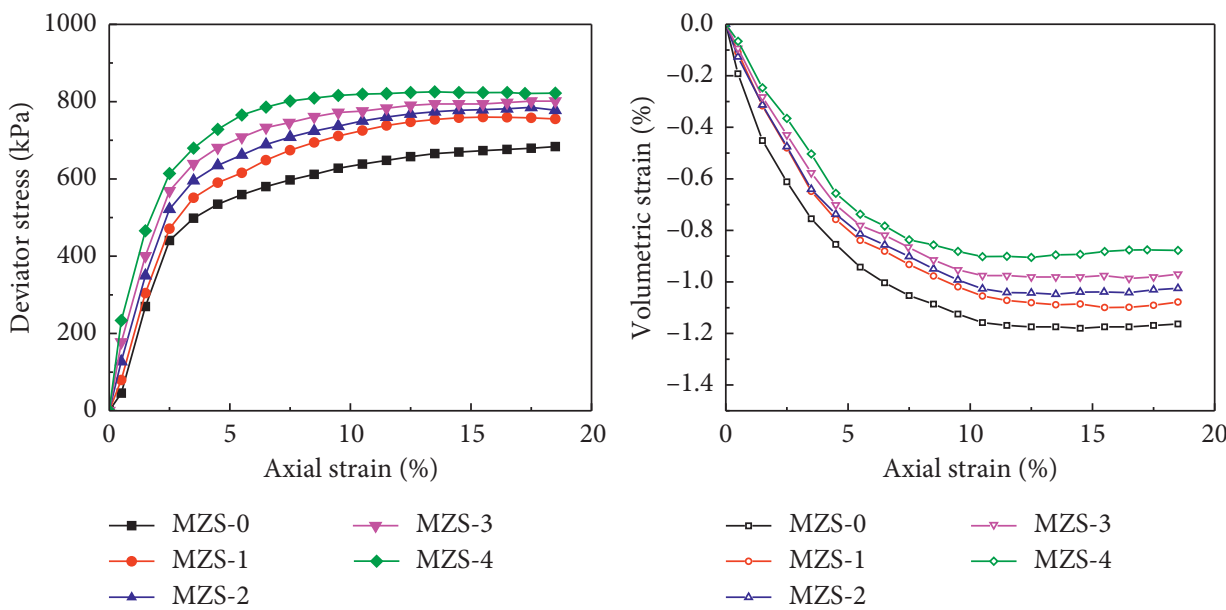

(d)

FiguRE 8: Drained shear (CDC) behavior of treated loess with different contents of lignin at different effective confining pressures. (a) $80 \mathrm{kPa}$. (b) $140 \mathrm{kPa}$. (c) $200 \mathrm{kPa}$. (d) $300 \mathrm{kPa}$.

from 80 to $300 \mathrm{kPa}$. The loess samples containing $4 \%$ lignin exhibited a maximum dilation at a confining pressure of $80 \mathrm{kPa}$ and compression at a confining pressure of $300 \mathrm{kPa}$. This finding suggests that the effective confining pressure significantly affects the total volume change of the treated loess. Valley depth, which determines the effective confining pressure, should thus be considered when selecting appropriate fill materials.

The results of both the ICUC and CDC tests indicated that the addition of lignin increased the shear strength of loess. The deviator stress was nearly constant when the axial strain was $15 \%$. Stress-strain relationships from both tests also showed a strain-hardening behavior in the treated (1-4\% lignin) loess samples. However, in the untreated $(0 \%$ lignin) loess samples, the stress-strain relationships differed between the two tests. In the ICUC tests, the untreated samples showed a strain-softening behavior, while in the CDC tests, the untreated samples showed a strain-hardening behavior. This latter finding indicating a strain-hardening behavior is consistent with previously reported findings [33-35].
3.4. Scanning Electron Microscopy (SEM) Analysis. To analyze the mechanical effects of lignin, scanning electron microscopy (SEM) was used to compare the microstructures of the treated ( $1-4 \%$ lignin) and untreated ( $0 \%$ lignin) loess samples. Figure 9 shows the results of this analysis.

In the untreated loess samples, the clay particles were adhered to larger particle surfaces. The grain outlines were distinct, and the adhesive material between particles was minimal. The embedded particles were compact but joined only by point contacts with obvious open voids. The pore structures in these samples were generally uniform.

In the treated loess samples, the adhesive content on the large particle surfaces increased as the lignin content increased. When the lignin content was $1-2 \%$, the adhesive content on the silt $(0.005-0.05 \mathrm{~mm})$ and sand $(>0.05 \mathrm{~mm})$ surfaces increased, and the interparticle contact mode changed from point to surface contacts, which increased the material's macroscopic mechanical properties. When the lignin content was $3-4 \%$, the banded lignin fibers were apparent in a randomly distributed pattern around the loess particles. In these samples with higher lignin contents, the 


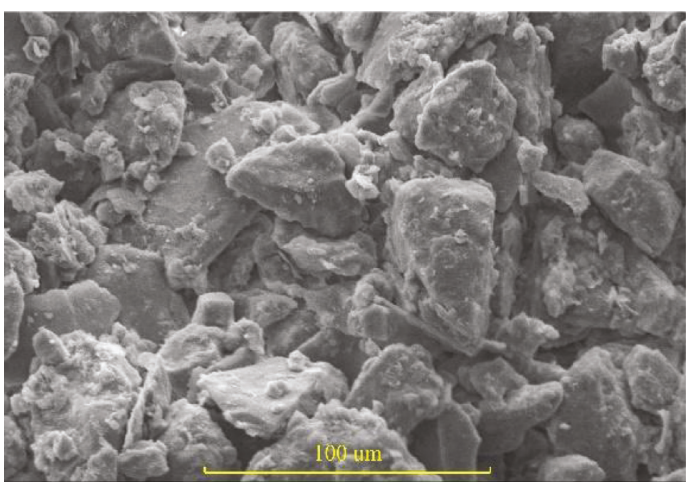

(a)

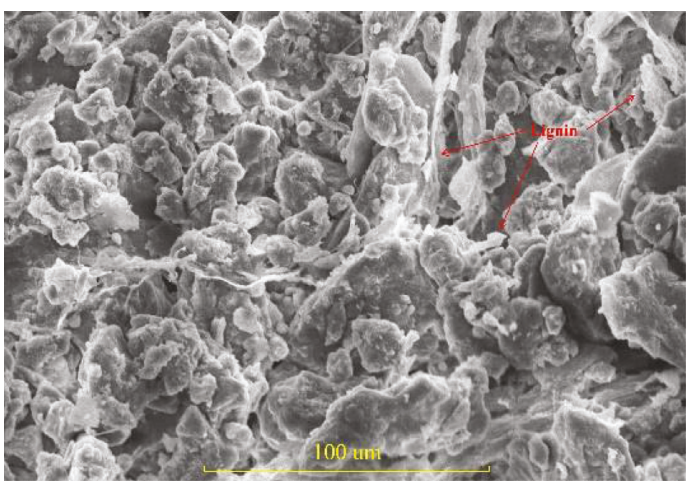

(c)

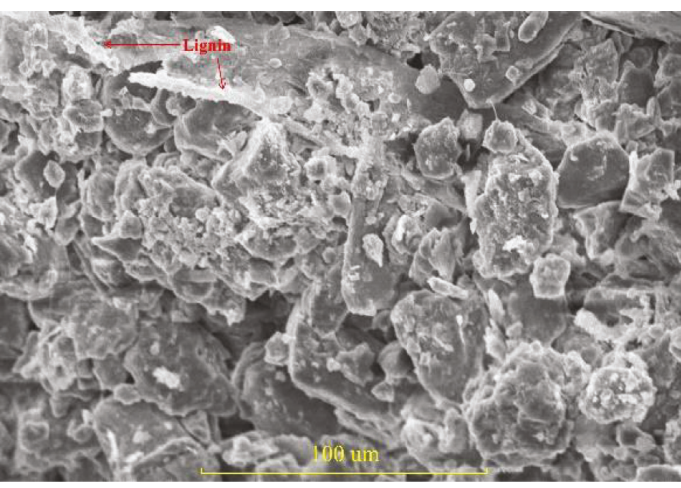

(b)

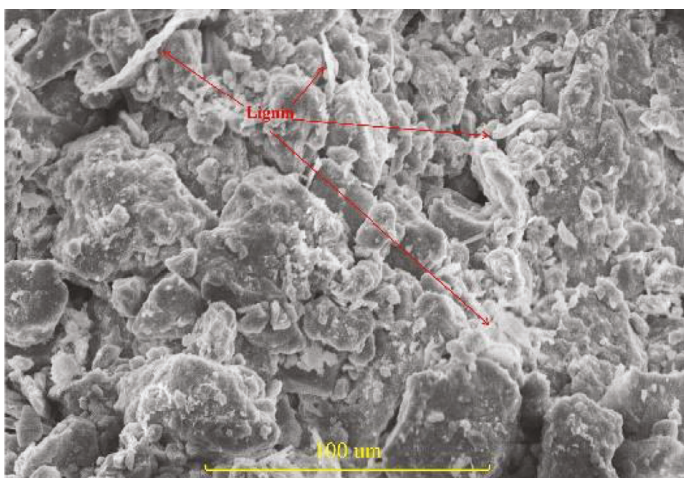

(d)

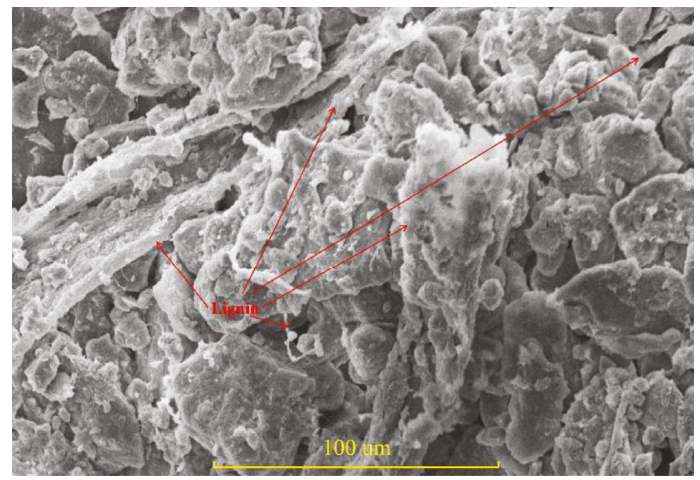

(e)

FIGURE 9: SEM results of treated loess with different contents of lignin. (a) MZS-0. (b) MZS-1. (c) MZS-2. (d) MZS-3. (e) MZS-4.

content of linear-shaped (strip) lignin fibers increased significantly, the adhesive content on the large particle surfaces increased, and loess particle aggregation increased. These collective findings suggest that the increased strength of lignin-treated loess is primarily attributable to the increase in strip lignin fibers and adhesion in the material's microstructure.

3.5. X-Ray Diffraction (XRD) Analysis. To supplement the findings of the SEM analysis, X-ray diffraction (XRD) was used to compare the mineral compositions of the treated (1-4\% lignin) and untreated (0\% lignin) loess samples. The specific mineral composition of the loess included hornblende, gypsum, quartz, feldspar, calcite, pyroxene, and kaolin. Table 2 details the content of each mineral in the test samples used in this study.

The mineral compositions of the treated and untreated loess samples were nearly consistent. In the treated loess samples, the clay mineral content was generally higher and increased as the lignin content increased. This finding suggests that an ion exchange occurs at certain water contents after the lignin is mixed with the loess, which results in the formation of new clay minerals and an increased clay mineral content.

\section{Conclusions}

In response to the need for an environmentally friendly alternative to conventional stabilizing additives (cement, 
TABLE 2: Mineral composition of loess and treated loess samples.

\begin{tabular}{lccccccc}
\hline Samples & Hornblende (\%) & Gypsum (\%) & Quartz (\%) & Feldspar (\%) & Calcite (\%) & Pyroxene (\%) & Kaolin (\%) \\
\hline MZS-0 & 4.20 & 1.19 & 35.50 & 16.80 & 11.87 & 5.00 & 25.44 \\
MZS-1 & 4.33 & 1.40 & 32.84 & 17.65 & 12.27 & 5.40 \\
MZS-2 & 5.12 & 1.20 & 32.68 & 18.24 & 8.42 & 6.10 \\
MZS-3 & 6.14 & 1.77 & 30.82 & 18.20 & 5.48 & 6.33 \\
MZS-4 & 6.00 & 1.65 & 30.71 & 19.55 & 0.79 & 7.85 & 31.26 \\
\hline
\end{tabular}

lime, and fly ash) used to improve the strength and durability of valley fill material, we considered the effects of lignin on loess shear strength. In this study, we tested 40 remolded loess samples treated with lignin. Triaxial tests, SEM, and XRD were used to study the mechanical characteristics of each sample, determine the effects of the lignin treatment on the loess, and identify the microscopic mechanism affecting shear stress in the lignin-treated loess. The corresponding development of excess pore pressure and volumetric responses under monotonic triaxial testing were also considered.

Based on the results of the UC tests, compressive strengths generally increased as lignin content increased. The optimum lignin content in the treated loess samples was $4 \%$. Lignin contents exceeding $4 \%$ decreased axial stress and increased dilation after saturation, which in turn affected the accurate test of mechanical properties.

Based on the results of the ICUC and CDC tests, shear strengths also increased as lignin content increased. Stressstrain relationships from both tests also showed a strainhardening behavior in the treated $(1-4 \%$ lignin) loess samples. However, in the untreated ( $0 \%$ lignin) loess samples, the stress-strain relationships differed between the two tests. In the ICUC tests, the untreated samples showed a strain-softening behavior, while in the CDC tests, the untreated samples showed a strain-hardening behavior. In the ICUC tests, the addition of lignin transformed the stressstrain relationship from strain softening to strain hardening, and the excess pore water pressure decreased as the strain increased. The decrease in excess pore water pressure is countered by the increase in shear strength. This collective behavior suggests good potential for lignin-treated loess in geotechnical engineering applications.

Results of the CDC tests also indicated the effects of different effective confining pressures on a material's shear strength. A dilative shear response was observed for samples tested at low confining pressures ( 80 and $140 \mathrm{kPa})$, while a contractive shear response was observed for samples subjected to higher confining pressures $(200$ and $300 \mathrm{kPa})$. In each case, the responses were magnified in the treated loess samples.

Finally, results from the SEM and XRD analyses indicated that the addition of lignin altered the pore structure and material composition of the loess. These changes to the material's microstructure increased cohesion in the loess samples, while slightly contributing to the internal friction angle. In samples with higher lignin contents (3-4\%), the increased strength of lignin-treated loess was primarily attributable to the increase in both strip lignin fibers and adhesion in the material's microstructure. Considering material composition, ion exchange following the addition of lignin resulted in the formation of new clay minerals and an increased clay mineral content.

Based on these collective results, the use of lignin as a stabilizing additive for valley fill material shows potential for controlling building foundation deformation by increasing soil strength. In addition, the use of lignin as an alternative stabilizing additive to cement, lime, and fly ash would minimize environmental impacts by maintaining the soil $\mathrm{pH}$ and limiting pollutant production.

\section{Data Availability}

The figures and tables reflecting data used to support the findings of this study are included within this paper.

\section{Conflicts of Interest}

The authors declare that there are no conflicts of interest regarding the publication of this paper.

\section{Acknowledgments}

The authors would like to thank Mr. Wang Jun (China Earthquake Administration and Gansu Province) for his useful guidance. The authors would also like to acknowledge Mr. Liu Zhaozhao (Lanzhou University) and Mr. Fan Wenjun (Lanzhou University) for their assistance in sampling. This work was supported by the Opening Fund of the Key Laboratory of Loess Earthquake Engineering, China Earthquake Administration, and Gansu Province (Grant KLLEE-17-004); National Natural Science Foundation of China (Grant 51778590); and Fundamental Research Funds for the Central Universities (Grant lzujbky-2017-170).

\section{References}

[1] Z. Metelková, J. Boháč, R. Přikryl, and I. Sedlářová, "Maturation of loess treated with variable lime admixture: pore space textural evolution and related phase changes," Applied Clay Science, vol. 61, pp. 37-43, 2012.

[2] S. R. Taylor, S. M. McLennan, and M. T. McCulloch, "Geochemistry of loess, continental crustal composition and crustal model ages," Geochimica et Cosmochimica Acta, vol. 47, no. 11, pp. 1897-1905, 1983.

[3] X. Xu, Q. Li, Y. Lai, W. Pang, and R. Zhang, "Effect of moisture content on mechanical and damage behavior of frozen loess under triaxial condition along with different confining pressures," Cold Regions Science and Technology, vol. 157, pp. 110-118, 2019.

[4] X. Xu, Y. Wang, Z. Yin, and H. Zhang, "Effect of temperature and strain rate on mechanical characteristics and constitutive 
model of frozen Helin loess," Cold Regions Science and Technology, vol. 136, pp. 44-51, 2017.

[5] W. W. Chen, W. Liu, J. Wang, G. P. Sun, and W. J. Wu, "Relationship of degree of saturation and B value of loess," Rock and Soil Mechanics, vol. 40, no. 3, pp. 834-842, 2019, in Chinese.

[6] J. B Mawulé Dassekpo, X. Zha, and J. Zhan, "Synthesis reaction and compressive strength behavior of loess-fly ash based geopolymers for the development of sustainable green materials," Construction and Building Materials, vol. 141, pp. 491-500, 2017.

[7] S. Lim, W. Jeon, J. Lee, K. Lee, and N. Kim, "Engineering properties of water/wastewater-treatment sludge modified by hydrated lime, fly ash and loess," Water Research, vol. 36, no. 17, pp. 4177-4184, 2002.

[8] O. Cuisinier, J.-C. Auriol, T. Le Borgne, and D. Deneele, "Microstructure and hydraulic conductivity of a compacted lime-treated soil," Engineering Geology, vol. 123, no. 3, pp. 187-193, 2011.

[9] Y. Gao, H. Qian, X. Li, J. Chen, and H. Jia, "Effects of lime treatment on the hydraulic conductivity and microstructure of loess," Environmental Earth Sciences, vol. 77, no. 14, pp. 529-544, 2018.

[10] Y. C. Zhang, Y. G. Yao, and H. Zhou, "Experimental study of shear strength and permeability of improved loess with long age," Rock and Soil Mechanics, vol. 38, no. 2, pp. 170-176, 2017, in Chinese.

[11] C.-L. Zhang, G.-L. Jiang, L.-J. Su, and G.-D. Zhou, "Effect of cement on the stabilization of loess," Journal of Mountain Science, vol. 14, no. 11, pp. 2325-2336, 2017.

[12] Y. Zhang, Z. Hu, L. Li, and Z. Xue, "Improving the structure and mechanical properties of loess by acid solutions-an experimental study," Engineering Geology, vol. 244, pp. 132-145, 2018.

[13] R. S. Rollings, J. P. Burkes, and M. P. Rollings, "Sulfate attack on cement-stabilized sand," Journal of Geotechnical and Geoenvironmental Engineering, vol. 125, no. 5, pp. 364-372, 1999.

[14] N. R. Kitchen, K. A. Sudduth, and S. T. Drummond, "Mapping of sand deposition from 1993 midwest floods with electromagnetic induction measurements," Journal of Soil and Water Conservation, vol. 51, no. 4, pp. 336-340, 1996.

[15] Z. Nalbantoglu and E. R. Tuncer, "Compressibility and hydraulic conductivity of a chemically treated expansive clay," Canadian Geotechnical Journal, vol. 38, no. 1, pp. 154-160, 2001.

[16] S. Goren and O. Alagha, "Soil treatment with lignin sulphide chemical stabilizer: environmental and structural assessment," Journal of Residuals Science and Technology, vol. 5, no. 4, pp. 189-194, 2008.

[17] B. Indraratna, T. Muttuvel, H. Khabbaz, and R. Armstrong, "Predicting the erosion rate of chemically treated soil using a process simulation apparatus for internal crack erosion," Journal of Geotechnical and Geoenvironmental Engineering, vol. 134, no. 6, pp. 837-844, 2008.

[18] B. Indraratna, R. Athukorala, and J. Vinod, "Estimating the rate of erosion of a silty sand treated with Lignosulfonate," Journal of Geotechnical and Geoenvironmental Engineering, vol. 139, no. 5, pp. 701-714, 2013.

[19] G. Cai, T. Zhang, S. Liu, J. Li, and D. Jie, "Stabilization mechanism and effect evaluation of stabilized silt with lignin based on laboratory data," Marine Georesources \& Geotechnology, vol. 34, no. 4, pp. 331-340, 2016.

[20] T. Zhang, S. Liu, G. Cai, and A. J. Puppala, "Experimental investigation of thermal and mechanical properties of lignin treated silt," Engineering Geology, vol. 196, pp. 1-11, 2015.
[21] T. Zhang, G. J. Cai, S. Y. Liu, and A. J. Puppala, "Engineering properties and microstructural characteristics of foundation silt stabilized by lignin-based industrial by-product," Ksce Journal of Civil Engineering, vol. 20, no. 7, pp. 1-12, 2016.

[22] T. Zhang, G. Cai, and S. Liu, "Application of lignin-based byproduct stabilized silty soil in highway subgrade: a field investigation," Journal of Cleaner Production, vol. 142, pp. 4243-4257, 2017.

[23] H. Canakci, A. Aziz, and F. Celik, "Soil stabilization of clay with lignin, rice husk powder and ash," Geomechanics and Engineering, vol. 8, no. 1, pp. 67-79, 2015.

[24] B. Xiao, X. F. Sun, and R. Sun, "The chemical modification of lignins with succinic anhydride in aqueous systems," Polymer Degradation and Stability, vol. 71, no. 2, pp. 223-231, 2001.

[25] K. Vasskog, B. C. Kvisvik, and Ø. Paasche, "Effects of hydrogen peroxide treatment on measurements of lake sediment grain-size distribution," Journal of Paleolimnology, vol. 56, no. 4, pp. 365-381, 2016.

[26] ASTM International, Standard Test Methods for Liquid Limit, Plastic Limit, and Plasticity Index of Soils. ASTM Standard D4318-10, ASTM International, West Conshohocken, PA, USA, 2010.

[27] ASTM International, Standard Test Methods for Laboratory Determination of Water (Moisture) Content of Soil and Rock by Mass. ASTM standard D2216-10, ASTM International, West Conshohocken, PA, USA, 2010.

[28] B. Chen, "Polymer-clay nanocomposites: an overview with emphasis on interaction mechanisms," British Ceramic Transactions, vol. 103, no. 6, pp. 241-249, 2004.

[29] J. Wang, Y. C. Shi, J. M. Wang, Q. Wang, and X. M. Zhong, "Comparative analysis of characters of loess subsidence under different seismic load," Chinese Journal of Geotechnical Engineering, vol. 33, no. 1, pp. 102-105, 2011, in Chinese.

[30] J. S. Vinod and B. Indraratna, "A conceptual model for lignosulfonate treated soils," in Proceedings of the 13th International Conference of the International Association for Computer Methods and Advances in Geomechanics, N. Khalili and M. Oeser, Eds., pp. 296-300, Centre for Infrastructure Engineering and Safety, Melbourne, Australia, May 2011.

[31] B. Indraratna, "Utilization of lime, slag and fly ash for improvement of a colluvial soil in New South Wales, Australia," Journal of Geotechnical and Geological Engineering, vol. 14, no. 3, pp. 169-191, 1996.

[32] Z. Liu, C. S. Cai, F. Y. Liu, and F. H. Fan, "Feasibility study of loess stabilization with fly ash-based geopolymer," Journal of Materials in Civil Engineering, vol. 28, no. 5, article 04016003, 2016.

[33] X. Qi, Q. Xu, and F. Liu, "Analysis of retrogressive loess flowslides in Heifangtai, China," Engineering Geology, vol. 236, pp. 119-128, 2018.

[34] L. Xu, F. C. Dai, L. G. Tham et al., "Field testing of irrigation effects on the stability of a cliff edge in loess, North-west China," Engineering Geology, vol. 120, no. 1-4, pp. 10-17, 2011.

[35] L. Xu, F. C. Dai, L. G. Tham, Y. F. Zhou, and C. X. Wu, "Investigating landslide-related cracks along the edge of two loess platforms in North-west China," Earth Surface Processes and Landforms, vol. 37, no. 10, pp. 1023-1033, 2012. 


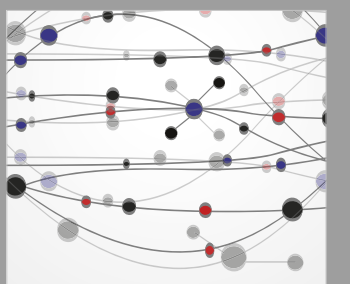

The Scientific World Journal
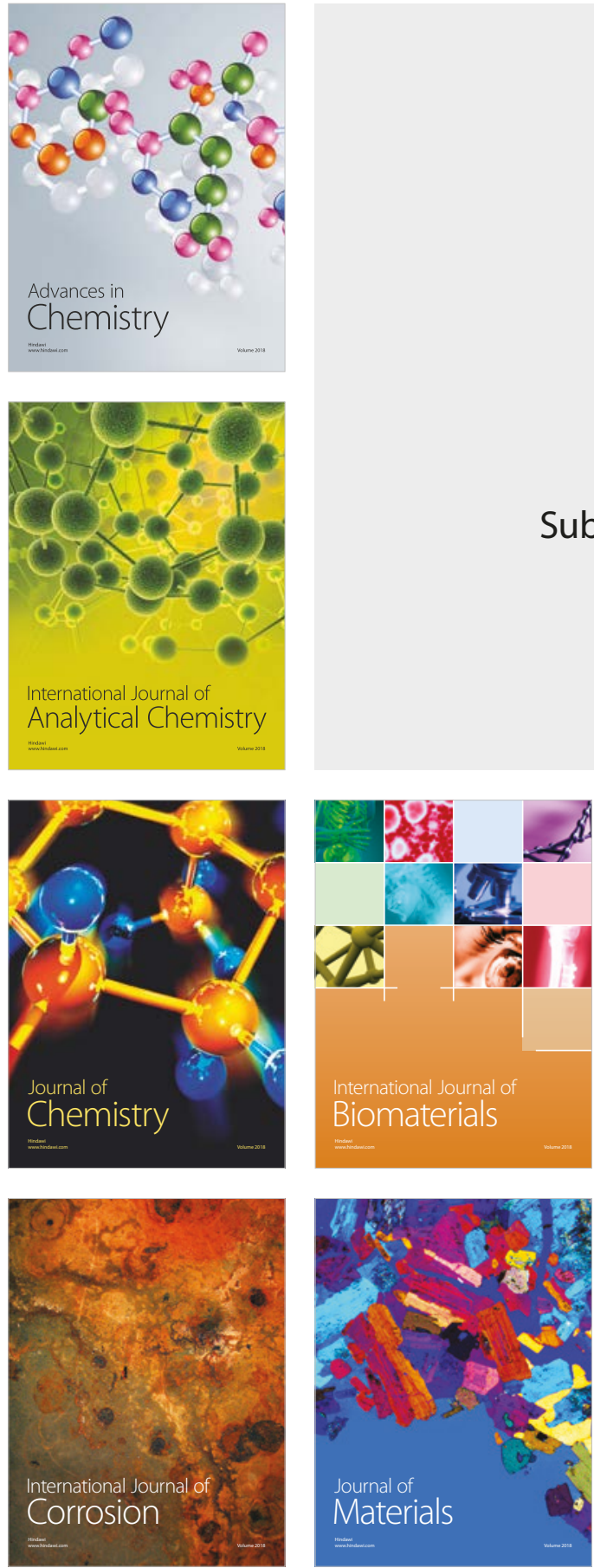

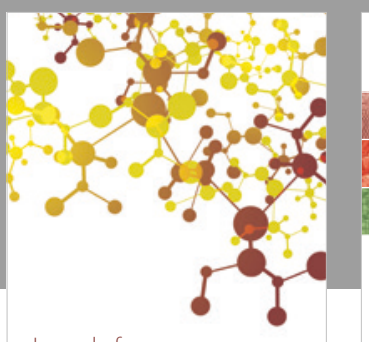

Journal of

Applied Chemistry
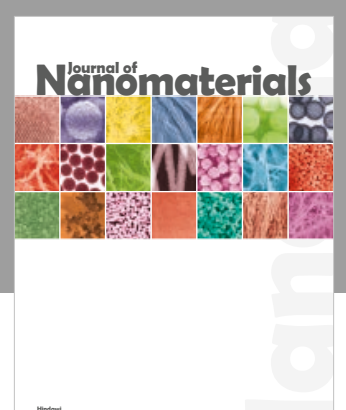

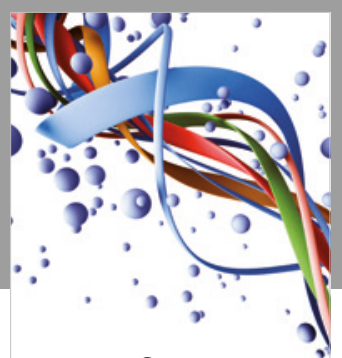

Scientifica

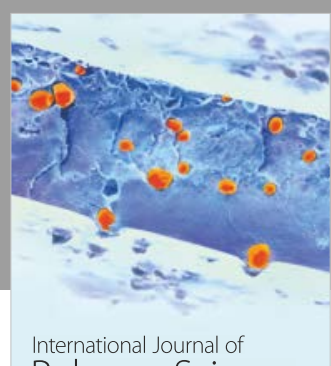

Polymer Science

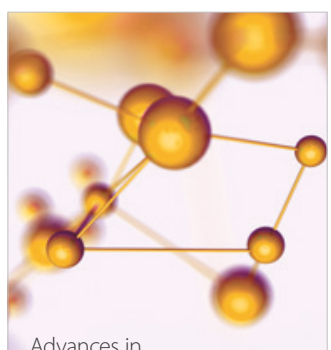

Physical Chemistry
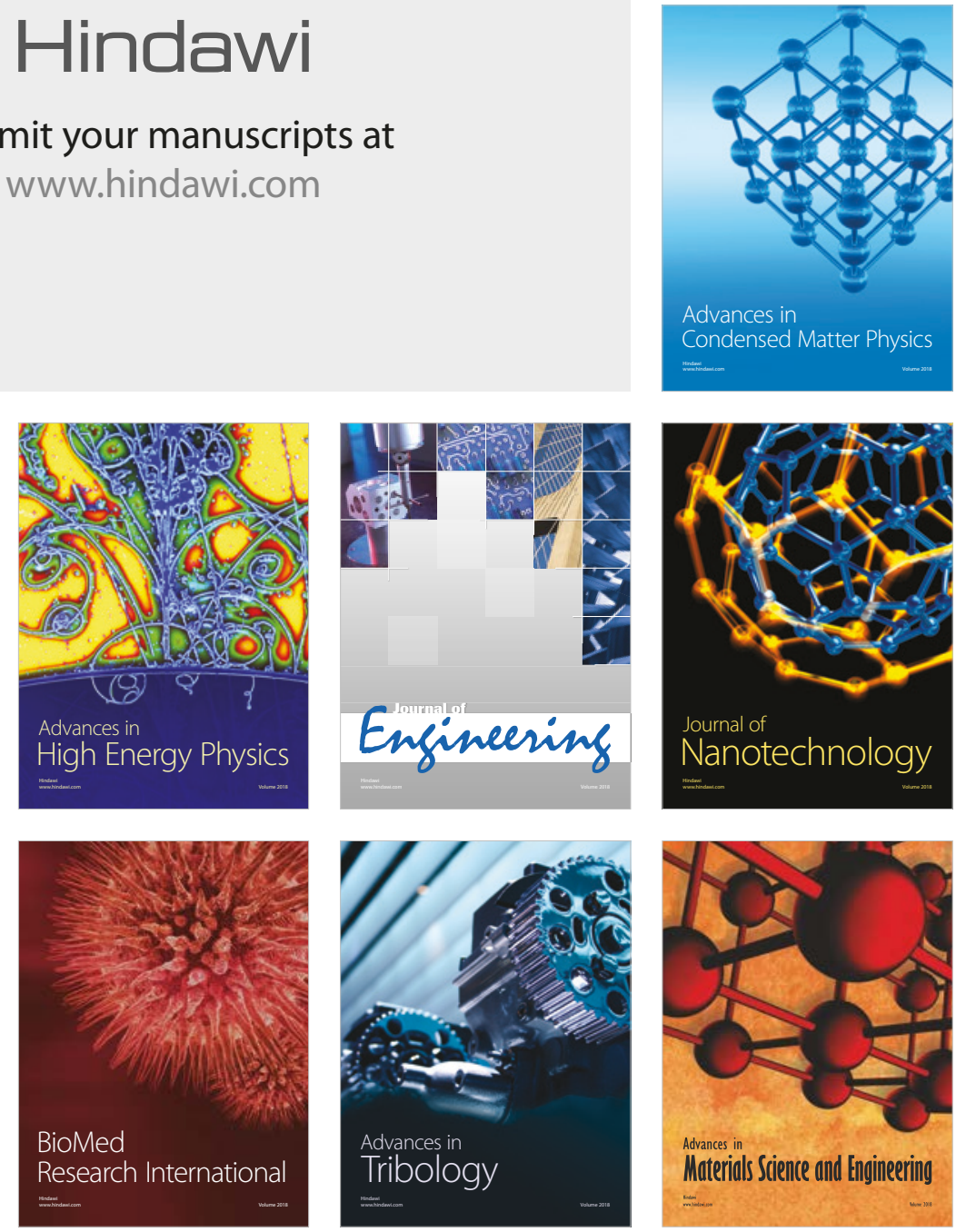